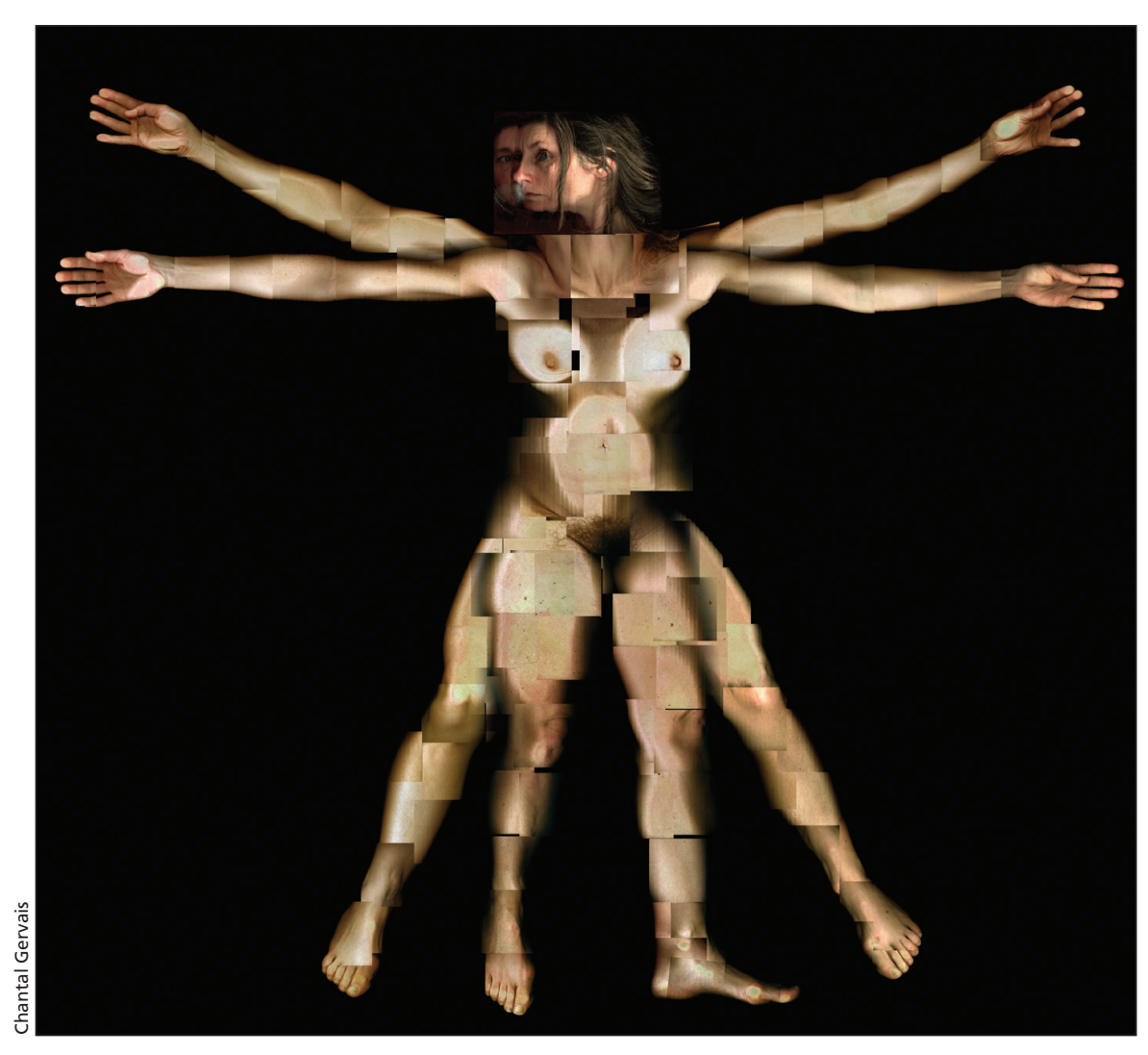

Chantal Gervais, "Vitruvian Me"(2008) from Les maux non dits. Inkjet print on polypropylene. $152 \times 172 \mathrm{~cm}$. Artist's collection.
Yellow spots mark the heels: could the Vitruvian woman have blisters?

One leaves the exhibit with mixed feelings. The inner beauty of the human body, its fragility, its profound aesthetic impact is clear. We are reminded of prehistoric Venus figurines, of silhouettes that children trace of themselves with markers onto large strips of paper: There is a definite impression of primitive art. However, at the same time, modern technology is at the core of Gervais' work; it could not exist without MRI and flatbed scans. This powerful duality destabilizes and intrigues, and by changing our view of the body could change our view of the world.

\section{Isabelle Leblanc MD \\ Family medicine \\ McGill University \\ Montréal, Que.}

\section{REFERENCES}

1. Gervais C, Stelmackowich C, Sudhoff S. Rx. IPS Exhibitions. Montréal (QC): 2009. Available: www .inplainsight.ca/en/exhibitions/2009/04/rx/index.php (accessed 2009 May 11).

2. Gervais C. Artist's website. Ottawa (ON); 2009. Available: www.artengine.ca/cgervais/ (accessed 2009 May 11).

\title{
Health disparities grow as people live longer
}

\author{
Global Health and Global Aging \\ Mary Robinson, William Novelli, Clarence \\ Pearson and Laurie Norris, editors \\ Jossey-Bass; 2007. \\ 373 pp \$55.00 (e-book available)
}

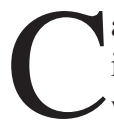

algary is aging, Canberra is aging, Calcutta is aging. The

world's population is getting older and it is doing so in almost every country. And if you harboured any doubts about this, take a quick look at this book. In 1949, the year I was born, the global population aged 60 or more accounted for only $8 \%$ of the total. By the time I die, say in 2070 , that figure will rise to $22 \%$. This forecast is both good and bad news, and this book examines both.
To begin with the half-full metaphor, the growth in the number of older folks is a paean to mankind's success in mitigating premature mortality — an absolute first in world history. Almost all of us want to live longer and now more actually do.

However, under the half-empty rubric, the aging of the population presents 2 major problems (happily, both are at least partially correctable through a combination of lifestyle choices and modern medicine).

The first problem involves the overall increase in the burden of age-related disease. While relatively, many older folks are staying healthier and often dying before they get sick, there are still, from an absolute point of view, more older people, some of whom will fall ill. Ergo, the world will have to cope with an overall increase in age-related disease and illness.

The second bit of bad news is that old age in the District of Columbia is not the same as old age in the State of Colombia. As is the case with another vulnerable group, children, we see that disparities in wealth and education translate almost directly into gaps in health status for older folks.

It may sound obvious, but very poor and old people in developing countries, have a much more difficult time of it than their counterparts in the developed world. As well, the dizzying speed of demographic change makes it difficult for many countries to cope. For example, it took almost 140 years for France's senior population to rise from $10 \%$ to $20 \%$ of the total. In contrast, it will take India 
fewer than 40 years to make this leap. Developing countries are transitioning even more rapidly. To put it another way, the developed regions first got rich, they then got old. In the developing regions, it is exactly the opposite - with unknown, but likely sobering implications.

The authors also assess countries that are enjoying high rates of longevity, such as Denmark, France and the United States. Comparatively speaking, Canada isn't doing too badly, but can certainly learn from the experiences of these others.

Another section of essays examines the challenges for countries facing rapid population aging in the next 20 to 30 years. Chapters on Africa, China, Latin America offer interesting perspectives.
For example, we learn about the effects of the HIV/AIDS epidemic in Africa and the implications for both grandparents and grandchildren of the "missing generation" of people between the ages of 20 and 40. The chapter on China deals with, among other things, the demographic effect of the low fertility policies of the current government.

The book concludes with an examination of research and program leaders, whose work ranges from biology to the effect of the new longevity on retirement security - an issue of no little importance given the recent economic downturn.

All in all, the aging of populations across the globe should be considered a great leap forward, reflecting a rousing victory over childhood disease and premature mortality. However, not all countries nor all people age equally well. And certainly, the poor grow old less salubriously and happily. This book offers much information and food for thought as we continue along life's journey - both as individuals as well as citizens of our aging planet.

\section{A. Mark Clarfield MD}

Department of Geriatrics, Soroka Hospital

Ben Gurion University of the Negev Beer-Sheva, Israel

Dr. Clarfield is the international affairs editor of the Journal of the American Geriatrics Society.

\section{Chisholm, WHO and the pursuit of the public's health}

\author{
Brock Chisholm, the World Health \\ Organization, and the Cold War \\ John Farley \\ UBC Press; 2008. 254 pp $\$ 85.00$
}

$\mathrm{W}$ hether by coincidence or by design, 4 remarkable books that express the ideal of peace through health, the goal of the World Health Organization, were published in 2008, coinciding with WHO's 60th anniversary. And to this Canadian reviewer the fact that all their authors and editors happen to be Canadian is an expression not of chauvinism, but of legitimate pride.

Crimes Against Humanity, by Adam Jones of the University of British Columbia Okanagan; this reviewer's book, Concepts and Practice of Humanitarian Medicine; Peace through Health (page xxx), by Neil Arya and Joanna Santa Barbara of McMaster University; and John Farley's book embody in their own ways what another Canadian, Dr. George Brock Chisholm (1896-1971), envisioned and practised as the first directorgeneral of WHO.

Based on an extensive search through the archives of WHO and related records, Brock Chisholm is an attempt by

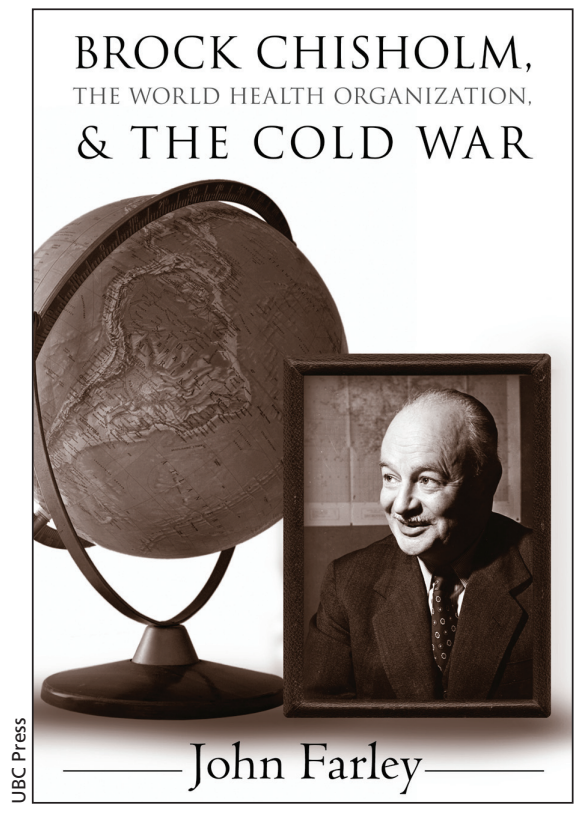

Farley, a Dalhousie University medical historian, to clarify the often entangled relationships between an idealistic leader, a fledgling organization for a new world order and a pitiless Cold War confrontation. Being by design limited in time and scope, the book is an insightful account of that first decade, without pretending to be a biography of Chisholm or the history of WHO. Nonetheless, much transpires on the personality of the leader, the politics of the organization, and the postwar competition of ideologies that soon turned into bitter animosity, considerably detracting from the objectives, performance and efficacy of the organization.

This book will be of interest to medical historians, health planners and social scientists and is a vast depository of documentation for Canadian politologues, students of health policy and international administrators.

The author begins with an account of Chisholm's life, from a young, decorated Ontario soldier to physician, psychiatrist, major-general, deputy minister of health at the federal level, representative to the United Nations and thence to WHO. In light of this exceptional professional climb, one wonders why Farley reports that "Chisholm had been a surprising choice" as the first director-general of WHO when no document or statement alludes to any surprise. Indeed, being initially sent from Health Canada to the UN might seem surprising, but once in the international milieu Chisholm persistently climbed by the votes of his peers, all experts and potential competitors. Norman Howard-Jones, the historian of WHO and no soft-spoken judge, is categorical about this: "He was the natural choice." 